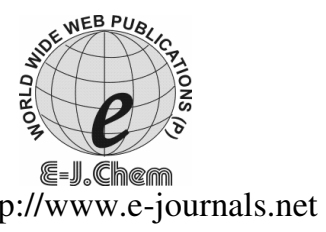

ISSN: 0973-4945; CODEN ECJHAO

E-Journal of Chemistry

2009, 6(4), 955-964

\title{
Development and Validation of LC Method for the Determination of Ampicillin and Dicloxacillin in Pharmaceutical Formulation Using an Experimental Design
}

\author{
TUSHAR .G. BAROT* ${ }^{*}$ KANHAIYALAL PATIDAR, \\ NAYAN KSHARTRI and NIRANJAN VYAS \\ Analytical Research Lab (ARL), \\ Cadila Pharmaceutical Ltd, Dholka, Gujarat, India. \\ barottrushar@gmail.com
}

Received 4 November 2008; Accepted 15 January 2009

\begin{abstract}
A simple, precise and accurate method to determine ampicillin and dicloxacillin in a pharmaceutical preparation capsule dosage form were developed and validated using liquid chromatography (LC). The LC separation was achieved on an ACE $150 \mathrm{~mm} \times 4.6 \mathrm{~mm}, 5 \mu$ in the isocratic mode using buffer: methanol $(40: 60, \mathrm{v} / \mathrm{v})$, as the mobile phase at a flow rate of $1.0 \mathrm{~mL} / \mathrm{min}$. The methods were performed at $220 \mathrm{~nm}$. In LC method, quantification was achieved with PDA detection over the concentration range of 50 to $150 \mu \mathrm{g} / \mathrm{mL}$. The methods were validated and the results were compared statistically. They were found to be simple, accurate, precise and specific. The methods were successfully applied for the determination of ampicillin and dicloxacillin in a pharmaceutical preparation capsule dosage form without any interference from common excipients. The proposed method was validated in terms of precision, robustness, recovery, LOD and LOQ. All the validation parameters were within the acceptance range.
\end{abstract}

Keywords: Ampicillin, Dicloxacillin, PDA detectiona, Liquid Chromatography.

\section{Introduction}

Ampicillin is known chemically (2S,5R,6R)-6-([(2R)-2-amino-2-phenylacetyl]amino)-3,3dimethyl-7-oxo-4-thia-1-azabicyclo[3.2.0]heptane-2-carboxylic acid. It has an emperical formula of $\mathrm{C}_{16} \mathrm{H}_{19} \mathrm{~N}_{3} \mathrm{O}_{4} \mathrm{~S}$ and a molecular weight of $349.409 \mathrm{~g} / \mathrm{mol}$.

Dicloxacillin is known chemically $(2 S, 5 R, 6 R)-6-\{[3-(2,6$-dichlorophenyl)-5-methyloxazole-4-carbonyl]amino\}-3,3-dimethyl-7-oxo-4-thia-1-azabicyclo[3.2.0]heptane-2-carboxylic acid. It has an emperical formula of $\mathrm{C}_{19} \mathrm{H}_{17} \mathrm{~N}_{3} \mathrm{O}_{5} \mathrm{~S}$ and a molecular weight of $470.327 \mathrm{~g} / \mathrm{mol}$. 
Ampicillin is beta-lactam antibiotic that has been used extensively to treat bacteria infections since 1961. It is considered part of the aminopenicillin family and is roughly equivalent to amoxicillin in terms of spectrum and level of activity. It can be used with cloxacillin as well as a powder ampicillin is white with slight yellow cast and is soluble in water.

Ampicillin, a potent antibiotic with relatively short-termed stability in aqueous solutions ${ }^{1,2}$ is used clinically to treat a broad range of bacterial infections ${ }^{3-5}$. With parenteral injection, ampicillin is distributed rapidly and widely, resulting in a high concentration of the drug in bile ${ }^{6}$. From bile, it is excreted into the gut and is known to cause disruption of the normal intestinal microflora by diminishing the main flora and increasing the presence of yeast as well as inducing a high risk of Clostridium difficile colitis ${ }^{7}$.

Dicloxacillin (INN) is a narrow spectrum of the penicillin class. It is used to treat infections caused by susceptible gram-positive bacteria. It is very similar to flucloxacillin and these two agents are considered interchangeable.

Dicloxacillin is more acid-stable than many other penicillins and can be given orally, in addition to parenteral routes. However, like methicillin, it is less potent than benzylpenicillin against non- $\beta$-lactamase-producing gram-positive bacteria.

A significant improvement in antibiotic activity and a reduction of the allergic and toxic reactions to ampicillin ${ }^{8,9}$ have been obtained by topical formulations ${ }^{10,11}$. The advantage of transdermal delivery of hydrophilic drugs versus oral delivery lies in the molecular nature of the gastrointestinal tract (GIT) ${ }^{12}$. As a lipid membrane, the GIT possesses hydrophobic properties; thus, the more hydrophilic a drug is, the more likely it is to be absorbed poorly through the GIT. Moreover, the amino group in ampicillin confers ${ }^{13}$ an ability to cross the cell wall barrier that is impenetrable to other types of penicillin. Owing to the above conditions, ampicillin developed as a membrane-moderated transdermal patch with a hydrophilic membrane was found to increase the permeation of hydrophilic drug; it was reported that the hydrophilic matrix modified with hydrophilic membrane ${ }^{14}$.

This paper describes precise, accurate and specific spectrophotometer and LC methods for determination of ampicillin and dicloxacillin in pure powder and capsules dosage form. A review of its preparation ${ }^{15-18}$, pharmacology ${ }^{19-21}$, drug interaction, chiral synthesis, structure activity study, clinical comparison with ampicillin and dicloxacillin, metabolism, pharmacokinetic and clinical experience review and clinical evaluation have been published recently.

Literature survey revealed the analytical method for determination of ampicillin and dicloxacillin have been reported and include high performance liquid chromatography (HPLC) method for determination of ampicillin and dicloxacillin in plasma ${ }^{22}$. LC-tandem mass spectrometry (LC-MS/MS) for determination of ampicillin and dicloxacillin in human plasma HPLC-MS/MS with electro spray ionization for determination of ampicillin and dicloxacillin in human plasma. This paper describes precise, accurate and specific spectrophotometer and LC methods for determination of ampicillin and dicloxacillin in capsules dosage form.

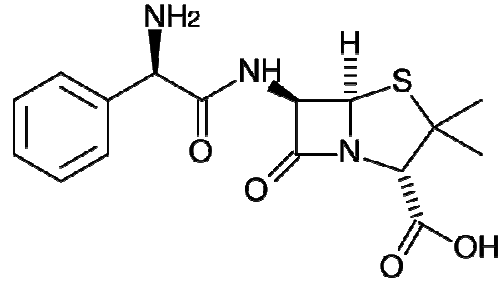

Ampicillin

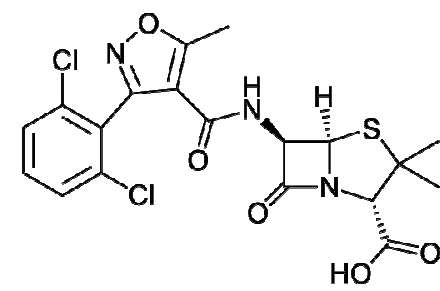

Dicloxacillin 


\section{Experimental}

HPLC grade acetonitrile and methanol, di-ammonium hydrogen orthophosphate and tetra butyl ammonium hydrogen sulphate were used to prepare the mobile phase and were purchased from Sigma-Aldrich (Milan, Italy). The working standard of ampicillin trihydrate (Lot no: QC/A-06-1/JAN08) and dicloxacillin sodium (Lot no: AR/WS/DICL-23/07) were purchased from Fluka (Milan, Italy). Deionized and purified water using a Mili-Q system (Milli-pore) was used for the mobile phase and the standard solutions preparation. All other reagents were of analytical grade.

\section{Chromatographic system}

The liquid chromatograph consisted of a dionex system, equipped with a P 680 HPLC Pump, an ASI-100 automatic sample injector and thermostatted column compartment TCC-100 and solvent Rack SOR-100. For data collection and calculation Empower software was used.

\section{Buffer preparation}

$2.64 \mathrm{~g}$ of di-ammonium hydrogen orthophosphate and $13.56 \mathrm{~g}$ of tetrabutyl ammonium sulphate was dissolved in $1000 \mathrm{~mL}$ water. The $\mathrm{pH} 7.0$ was adjusted with diluted sodium hydroxide solution.

The chromatographic conditions were optimized using a column ACE-5 (150 mmx 4.6 $\mathrm{mm}, 5 \mu \mathrm{m})$. The mobile phase consisted of methanol: phosphate buffer $(60: 40, \mathrm{v} / \mathrm{v})$. The mobile phase was filtered through a $0.22 \mu \mathrm{m}$ nitrocellulose-membrane filter (Milipore, Barcelone) and degassed under vacuum prior to use. The flow rate was $1.0 \mathrm{~mL} / \mathrm{min}$. The monitoring wavelength was $220 \mathrm{~nm}$ and the injection volume was $10 \mu \mathrm{L}$. Column oven was at $30^{\circ} \mathrm{C}$, peak area was measured and HPLC analysis was conducted at room temperature. A diluent mixture of 50 volumes of Milli Q water and 50 volumes of acetonitrile was prepared.

\section{System suitability standard solution}

$57 \mathrm{mg}$ of amplicillinn trihydrate, $55 \mathrm{mg}$ dicloxacillin sodium working standard was weighed and transferred in $200 \mathrm{~mL}$ volumetric flask. $100 \mathrm{~mL}$ of diluent was added and sonicated again 5 minutes, cooled and made up to volume with diluent $(285 \mu \mathrm{g} / \mathrm{mL}$, and $275 \mu \mathrm{g} / \mathrm{mL})$. The stability of the standard solutions was checked over this period by preparing and injecting daily a solution of the analyte (Figure 1).

5 Capsules were accurately weighed and transfered into $250 \mathrm{~mL}$ volumetric flask. $100 \mathrm{~mL}$ diluent was added and sonicated for 10 minutes and made up to the volume with diluent. This solution was then filtered through a $0.45 \mu \mathrm{m}-47 \mathrm{~mm}$ nylon membreane filter (Millipore, Barcelona). Further, $5 \mathrm{~mL}$ of this solution was added to 100 flask and diluted with diluent and mixed well.

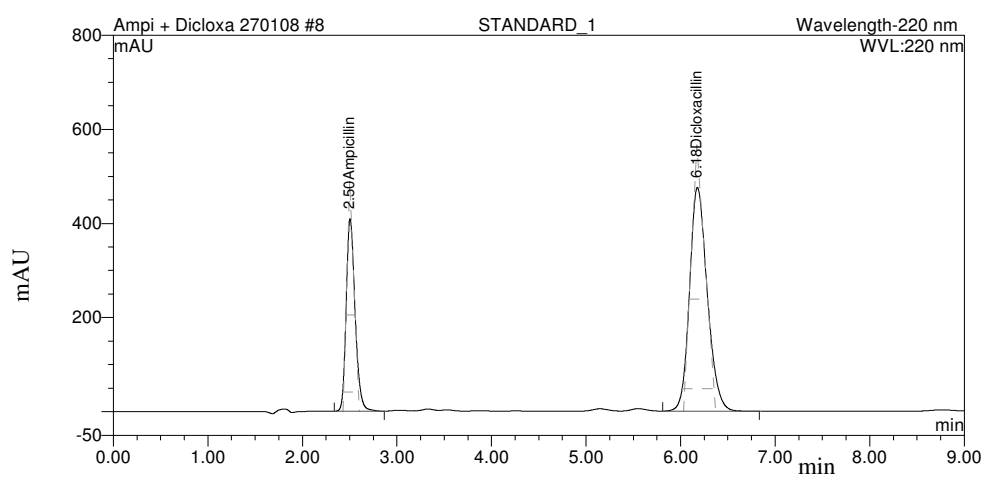

Figure 1. STD chromatogram of ampicilline trihydrate and dicloxacillin 


\section{Validation study}

\section{Specificity (Placebo interference)}

Specificity of an analytical method is its ability to measure accurately and specifically the analytical of interest without interference from placebo and diluent. Specificity of the method is demonstrated by preparing the solutions given below:

1. Mobile phase

2. Diluent

3. Standard Preparation

4. Placebo solution in triplicate

5. Placebo spiked with API at target concentration

6. Sample solution

Each solution was injected on to the chromatograph equipped with photo diode array detector. The chromatograms were recorded and observed the interference of diluent and placebo with the analyte peaks. The peak purity of analyte peak in placebo spiked with API and sample solution were also measured.

\section{Placebo preparation for $250 \mathrm{mg}$}

Accurately weighed $90 \mathrm{mg}$ of placebo was added to a $250 \mathrm{~mL}$ volumetric flask. About $100 \mathrm{~mL}$ of diluent was added and sonicated for $20 \mathrm{~min}$, cooled and diluted to volume with diluent and mixed. The resulting solution was filtered through nylon filter of $0.45 \mu$ discarding first few $\mathrm{mL}$ of filtrate. Further, $5 \mathrm{~mL}$ of this solution was added to $100 \mathrm{~mL}$ with diluent and mixed well $(18 \mu \mathrm{g} / \mathrm{mL})$.

\section{Placebo spike with API}

$90 \mathrm{mg}$ of placebo $(45 \mu \mathrm{g} / \mathrm{mL}), 1425 \mathrm{mg}$ ampicillin trihydrate $(712.5 \mu \mathrm{g} / \mathrm{mL})$ and $1375 \mathrm{mg}$ of dicloxacillin sodium $(687.5 \mu \mathrm{g} / \mathrm{mL})$ of API was accurately weighed and transferred into a $100 \mathrm{~mL}$ of diluents and sonicated for $30 \mathrm{~min}$. Further dilution was made with $5 \mathrm{~mL}$ of this solution to $100 \mathrm{~mL}$ with diluent and was mixed well.

\section{Method precision}

For six consecutive times, a same standard solution prepared according the described method, was injected. The standard deviation and the relative standard deviation (R.S.D) were calculated for six injections. For acceptance, the R.S.D. value must be smaller than $1.5 \%$ (Figure 2).

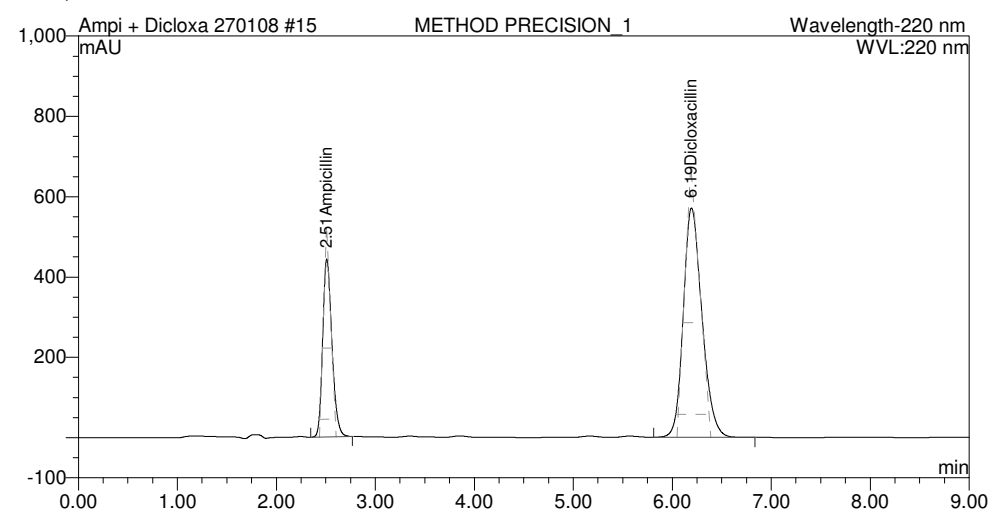

Figure 2. Chromatogram of method of precision of ampicilline trihydrate and dicloxacillin. 


\section{Intermediate precision}

The purpose of this experiment is to prove the reliability of the assay results obtained by this method with the changes like day to day, analyst to analyst, instrument to instrument and column to column.

\section{Accuracy (recovery method)}

Accuracy of a method is defined as the closeness of the measured value to the true value for the sample. The recovery method was studied at concentration levels of 50\%, 100\% and $150 \%$ of the claimed content, in presence of placebo. Each solution was injected three times. The recovery was calculated with respect to the standard solutions.

\section{Linearity}

The linearity study verifies that the sample solutions are in a concentration range where analyte response is linearly proportional to the concentration. This study was performed by evaluating the system and method linearity. For the system linearity, standard solutions of ampicillin and dicloxacillin at five concentration levels, from 50, 60, 80, 100, 120 and 150\% of the target analyte concentration, were prepared. The concentration were ampicillin 125 , 150, 200250,300 and $375 \mu \mathrm{g} / \mathrm{mL}$. The concentrations of dicloxacillin were 129, 155, 207, 258, 310 and $387 \mu \mathrm{g} / \mathrm{mL}$. Each level of concentration was prepared in triplicate. The experimental results were graphically plotted, obtaining a calibration curve and carrying out the corresponding statistical study.

\section{Stability in analytical solution}

The purpose of this experiment is to demonstrate the stability of standard and sample solution used in this method at room temperature (about $25^{\circ} \mathrm{C}$ ). The standard solution and sample solution was prepared as given in the methodology. Both the solutions were injected on to the chromatograph and recorded the chromatograms at regular interval up to $24 \mathrm{~h}$ for standard solution and sample solution. The peak response for the major peak was measured and evaluated the percentage deviation in the peak response from initial for both standard and sample solution.

\section{Robustness}

Three sample solutions of same lot of ampicillin and dicloxacillin were prepared as per method and analyzed using different chromatographic condition as below (Table 7).

1. Changing the flow rate of mobile phase $\pm 10 \%$ (i.e. $0.90 \mathrm{~mL} / \mathrm{min}$ and $1.10 \mathrm{~mL} / \mathrm{min}$ )

2. Changing the organic composition of mobile phase $\pm 5.0 \%$.

3. Changing the $\mathrm{pH}$ of buffer solution by \pm 0.2 unit (i.e. 6.8 and 7.2)

4. Changing the temp of column temperature by $+5{ }^{\circ} \mathrm{C}$ (i.e. $25^{\circ} \mathrm{C}$ and $35^{\circ} \mathrm{C}$ )

5. Changing the wavelength of detector by $\pm 2 \mathrm{~nm}$ (i.e. $218 \mathrm{~nm}$ and $222 \mathrm{~nm}$ )

\section{Results and Discussion}

\section{Method development}

The introduction of new HPLC methods for a routine quality control of pharmaceutical preparations begins with a series of preliminary investigations, which enables establishing the optimal experimental conditions and provide maximum relevant information by analyzing the experimental data. In this study, a RP-HPLC method for the determination of ampicillin and dicloxacillin was developed and validated. A simple sample preparation, short separation time was considered when the study started. 


\section{Validation study}

\section{Specificity}

From the ampicillin and dicloxacillin chromatogram, it was observed that the drug eluted at a retention time of 2.50 , and $6.18 \mathrm{~min}$. The study of the purity of the peak showed that the three spectrums obtained at different times are within the established threshold for this peak.

No interferences with the analyte peaks due to placebo or blank have been observed. On the basis of that, the method results specific for the quail-quantitative analysis of ampicillin and dicloxacillin.

The peak purity angle should be less than peak purity threshold or peak purity of analyte peak should not be less than 990 . Indicating that all peaks are pure Table 4 \& 5. According to the areas obtained, it can be concluded that all are stable in these conditions. The purity factor for the drug assures that there is no co elution of other peaks. Therefore, the method is selective and suitable for routine work.

\section{Precision}

\section{Repeatability}

As defined in the International Conference on Harmonization (ICH) guidelines, repeatability expresses the precision under the same operating conditions over a short interval of time. ICH guideline suggest a minimum of six readings of a single sample at $100 \%$ of a target concentration.

\section{Method precision}

The repeatability of the instrumental system was evaluated with this parameter. In this study, a R.S.D. of $1.8 \%$ and $1.9 \%$ were obtained by injecting a sample solution. $\%$ RSD for method precision results of six sample preparation should be NMT $2.0 \%$. The low \% RSD has observed for the six assay results hence it concluded that the method is precise for the analysis of ampicillin and dicloxacillin in ampicillin and dicloxacillin capsules Table 1.

Table 1. System suitability data for method precision of amiciline and dicloxacillin capsule dosage form.

\begin{tabular}{ccc}
\hline S. No. & Ampiciliin & Dicloxacillin \\
\hline 1 & $98.1 \%$ & 108.0 \\
2 & $98.3 \%$ & 108.2 \\
3 & $98.5 \%$ & 104.5 \\
4 & $99.2 \%$ & 105.2 \\
5 & $101.5 \%$ & 103.3 \\
6 & $102.4 \%$ & 104.2 \\
Mean & 99.7 & 105.6 \\
\% RSD & 1.8 & 1.9 \\
\hline
\end{tabular}

\section{Intermediate precision}

The results obtained meet the acceptance criteria of ruggedness, this indicates that the method is rugged for the analysis of ampicillin and dicloxacillin in ampicillin and dicloxacillin capsules. The difference between percentage assay results of method precision and intermediate precision should be NMT $2.0 \%$. Calculated the percentage assay of each sample and demonstrated the precision by evaluating percentage relative standard deviation of assay results. Compared the percentage assay results of altered conditions with normal conditions. 


\section{Accuracy}

The results obtained for the accuracy study in the samples ranging ampicillin concentration between $1.4,0.28$ and $0.43 \mathrm{mg} / \mathrm{mL}$ and being the $100 \%$ corresponding to $0.28 \mathrm{mg} / \mathrm{mL}(\mathrm{n}=6$ for $50 \%, 100 \%$ and $150 \%$ ) indicated that the recovery percent was between 98.5 and $99.5 \%$ of recovery (Table 2).

Table 2. Accuracy of the method for the determination of amiciline and dicloxacillin capsule dosage form.

\begin{tabular}{ccccc}
\hline S. No. & $\begin{array}{c}\text { \% Recovery of } \\
\text { ampicillin }\end{array}$ & $\begin{array}{c}\% \\
\text { Recovery }\end{array}$ & $\begin{array}{c}\text { Average of } \\
\% \text { recovery }\end{array}$ & $\begin{array}{c}\% \\
\text { RSD }\end{array}$ \\
\hline 1 & $50 \%$ sample set 1 & 98.17 & & \\
2 & $50 \%$ sample set 2 & 100.18 & 99.5 & 1.1 \\
3 & $50 \%$ sample set 3 & 100.10 & & \\
4 & $100 \%$ sample set 1 & 98.05 & & \\
5 & $100 \%$ sample set 2 & 98.49 & 98.5 & 0.5 \\
6 & $100 \%$ sample set 3 & 99.00 & & \\
7 & $150 \%$ sample set 1 & 98.99 & & \\
8 & $150 \%$ sample set 2 & 100.01 & 99.2 & 0.7 \\
9 & $150 \%$ sample set 3 & 98.73 & & \\
\hline
\end{tabular}

The results obtained for the accuracy study in the samples ranging dicloxacillin concentration between $0.13,0.27$ and $0.41 \mathrm{mg} / \mathrm{mL}$ and being the $100 \%$ corresponding to $0.27 \mathrm{mg} / \mathrm{mL}$ ( $\mathrm{n}=6$ for $50 \%, 100 \%$ and $150 \%$ ) indicated that the recovery percent was between 98.4 and $100.0 \%$ of recovery (Table 3 ).

Table 3. Accuracy of the method for determination of amiciline and dicloxacillin capsule dosage form.

\begin{tabular}{ccccc}
\hline S. No. & $\begin{array}{c}\text { \% Recovery of } \\
\text { Dicloxacillin }\end{array}$ & $\begin{array}{c}\% \\
\text { Recovery }\end{array}$ & $\begin{array}{c}\text { Average of } \\
\text { \% recovery }\end{array}$ & $\begin{array}{c}\% \\
\text { RSD }\end{array}$ \\
\hline 1 & $50 \%$ sample set 1 & 98.03 & & \\
2 & $50 \%$ sample set 2 & 99.57 & 98.7 & 0.8 \\
3 & $50 \%$ sample set 3 & 98.46 & & \\
4 & $100 \%$ sample set 1 & 98.18 & & \\
5 & $100 \%$ sample set 2 & 98.54 & 98.4 & 0.2 \\
6 & $100 \%$ sample set 3 & 98.53 & & \\
7 & $150 \%$ sample set 1 & 100.01 & & \\
8 & $150 \%$ sample set 2 & 100.58 & 100.0 & 0.5 \\
9 & $150 \%$ sample set 3 & 99.48 & & \\
\hline
\end{tabular}

$\%$ Recovery for the range 50 to $150 \%$ of target concentration has found within the acceptance criteria with acceptable \% RSD of NMT 2.0 at each level. The \% recovery at each level must be $98.0 \%$ to $102.0 \%$. This indicates that the method is accurate for the analysis of ampicillin and dicloxacillin in ampicillin and dicloxacillin capsules.

\section{Linearity}

Linearity is the ability of the method to respond proportionally to the changes in concentration or amount of the analyte in a sample. In routine, univariate calibration method linearity is established within a specific range. 
The calibration curve obtained by plotting the ampiciline and dicloxacillin peak area versus the concentration of standard solution is linear in the above mentioned concentration range.

Correlation coefficient of linearity plot should be not less than 0.990. Y-intercept bias should be within $\pm 2.0 \%$ linearity level response. This indicates that the method is linear up to the specified range for the analysis of ampicillin and dicloxacilline in ampicillin and dicloxacillin capsules (Table 4 \& 5).

Table 4. Evaluation of chromatographic parameter for ampicillin and dicloxacillin capsules dosage form.

\begin{tabular}{lcc}
\hline \multicolumn{1}{c}{ Compound } & Ampiciliin & Dicloxacillin \\
\hline R.T & 2.50 & 6.18 \\
K' USP & n.a & n.a \\
USP Tailing & 1.25 & 1.21 \\
No. of theoretical & 3485 & 5250 \\
plates (n) & & \\
Resolution & n.a. & 14.40 \\
\hline
\end{tabular}

Table 5. Evaluation of chromatographic parameter for ampicillin and dicloxacillin capsules dosage form.

\begin{tabular}{lcc}
\hline \multicolumn{1}{c}{ Parameter } & Ampiciliin & Dicloxacillin \\
\hline $\begin{array}{l}\text { Correlation } \\
\text { coefficient }\end{array}$ & 0.9995 & 0.9995 \\
$\begin{array}{l}\text { Residual standard } \\
\text { deviation }\end{array}$ & 34438.24 & 81911.54 \\
Slope & & \\
$Y$ - Intercept & 10517.05 & 23335.50 \\
$Y$ - Intercept bias & $1.86 \%$ & $1.35 \%$ \\
\hline
\end{tabular}

\section{Solution stability}

The solution stability was checked for sample preparation up to initial, $3,6,9,12,15,18,21$, and 24 hours. The results obtained are well within the acceptance criteria up to 24 hours at room temperature. Therefore, the sample preparation is stable for ampicillin and dicloxacillin in solution from up to 24 hours at room temperature. Both standard and sample solution thus prepared can be used within this time period. Results were determined and record in Table $6 \& 7$.

Table 6. Solution stability study analysis for ampicillin capsules dosage form.

\begin{tabular}{ccccc}
\hline $\begin{array}{c}\text { Time, } \\
\mathrm{h}\end{array}$ & $\begin{array}{c}\text { Peak response } \\
\text { for ampicillin } \\
\text { std solution }\end{array}$ & $\begin{array}{c}\text { \% Deviation } \\
\text { from initial }\end{array}$ & $\begin{array}{c}\text { Peak response } \\
\text { for ampicillin } \\
\text { sample solution }\end{array}$ & $\begin{array}{c}\text { \% Deviation } \\
\text { from initial }\end{array}$ \\
\hline Initial & 2676375.000 & - & 2882675.000 & - \\
3 & 2679278.000 & 0.1 & 2866361.000 & -0.6 \\
6 & 2692358.000 & 0.6 & 2859402.000 & -0.8 \\
9 & 2711531.000 & 1.3 & 2852759.000 & -1.0 \\
12 & 2724704.000 & 1.8 & 2847783.000 & -1.2 \\
15 & 2701961.000 & 1.0 & 2847814.000 & -1.2 \\
18 & 2651470.000 & -0.9 & 2839698.000 & -1.5 \\
21 & 2647556.000 & -1.1 & 2850547.000 & -1.1 \\
24 & 2651642.000 & -0.9 & 2850669.000 & -1.1 \\
\hline
\end{tabular}


Table 7. Solution stability study analysis for dicloxacillin capsules dosage form.

\begin{tabular}{ccccc}
\hline $\begin{array}{c}\text { Time, } \\
\mathrm{h}\end{array}$ & $\begin{array}{c}\text { Peak response for } \\
\text { dicloxacillin std } \\
\text { solution }\end{array}$ & $\begin{array}{c}\text { \% Deviation } \\
\text { from initial }\end{array}$ & $\begin{array}{c}\text { Peak response for } \\
\text { dicloxacillin } \\
\text { sample solution }\end{array}$ & $\begin{array}{c}\text { \% Deviation } \\
\text { from initial }\end{array}$ \\
\hline Initial & 6204789.000 & - & 7481747.000 & - \\
3 & 6205959.000 & 0.0 & 7440432.000 & -0.6 \\
6 & 6145668.000 & -1.0 & 7383455.000 & -1.3 \\
9 & 6290770.000 & 1.4 & 7399358.000 & -1.1 \\
12 & 6303830.000 & 1.6 & 7384705.000 & -1.3 \\
15 & 6323850.000 & 1.9 & 7394615.000 & -1.2 \\
18 & 6175087.000 & -0.5 & 7376906.000 & -1.4 \\
21 & 6177774.000 & -0.4 & 7413447.000 & -0.9 \\
24 & 6193636.000 & -0.2 & 7413505.000 & -0.9 \\
\hline
\end{tabular}

\section{Robustness}

Purpose of this experiment is to prove the reliability of the assay results obtained by this method with the minor but deliberate changes in analytical method parameter like flow rate, column oven temperature, detection wavelength and organic ratio of mobile phase Table 8 .

Table 8. Robustness study analysis for ampicillin and dicloxacillin capsules dosage form.

\begin{tabular}{lcc}
\hline \multicolumn{1}{c}{ Conditions } & $\begin{array}{c}\text { \% RSD for } \\
\text { Ampiciliin }\end{array}$ & $\begin{array}{c}\text { \% RSD for } \\
\text { Dicloxacillin }\end{array}$ \\
\hline Normal condition & 0.14 & 0.12 \\
Column temperature changed by $-5^{\circ} \mathrm{C}$, i.e. $25^{\circ} \mathrm{C}$ & 0.08 & 0.11 \\
Column temperature changed by $+5{ }^{\circ} \mathrm{C}$, i.e. $35^{\circ} \mathrm{C}$ & 0.17 & 0.18 \\
Flow rate changed by $-10 \%$, i.e. $0.90 \mathrm{~mL}$ & 0.13 & 0.14 \\
Flow rate changed by $+10 \%$, i.e. $1.00 \mathrm{~mL}$ & 1.45 & 1.19 \\
Wavelength of detector changed by $-2 \mathrm{~nm}$, i.e. $218 \mathrm{~nm}$ & 0.15 & 0.13 \\
Wavelength of detector changed by $+2 \mathrm{~nm}$, i.e. $220 \mathrm{~nm}$ & 0.15 & 0.11 \\
Organic ratio of mobile phase changed by $-5 \%$ relative & 0.15 & 0.18 \\
Organic ratio of mobile phase changed by $-5 \%$ relative & 0.42 & 0.11 \\
pH of buffer changed by -0.2 unit, i.e. 6.8 & 0.20 & 0.3 \\
pH of buffer changed by +0.2 unit, i.e. 7.2 & 0.2 & 1.2 \\
\hline
\end{tabular}

\section{Conclusions}

The proposed high performance liquid chromatographic method has been evaluated over the linearity, precision, accuracy, specificity and proved to be convenient and effective for the quality control of ampicillin and dicloxacillin in given application. It does not suffer any positive or negative interference due to common excipients present in formulations and can be conveniently used for routine quality control analysis. Thus, the proposed methodology is rapid, selective, requires a simple sample preparation procedure, and represents a good procedure of ampicillin and dicloxacillin determination in pharmaceutical dosage forms.

\section{Acknowledgement}

The authors are thankful to M/s Cadila Pharmaceutical Ltd, All raw data form the validation work archived at Cadila Pharmaceutical Ltd. All the validation work performed at Analytical Research Laboratory (ARL), Cadila Pharmaceutical Ltd, Dholka. 


\section{References}

1. $\quad$ Oliyai R and Lindenbaum S, Int J Pharm., 1991, 73, 33-36.

2. Carafa M, Marianecci C, Lucania G, Marchei E and Santucci E, J Control Release, 2004, 95, 67-74.

3. Ahren I L, Karlsson E, Forsgren A and Riesbeck K, J Antimicrob Chemother, 2002, 50, 903-906.

4. $\quad$ Rasheed A, Ravichandran V and Kohli DV, Pharmazie, 1999, 54, 857-858.

5. Mandell G L, Douglas R G Jr and Bennett J E, Eds. Principles and Practice of Infectious Diseases, $3^{\text {rd }}$ Ed., New York, NY, Churchill Livingstone, 1990, 240-242.

6. Acred P, Brown D M, Turner D H and Wilson M J, Br J Pharmacol Chemother, 1962 18, 356-369.

7. Harmoinen J, Vaali K, Koski P, Kaisa S and Outi L, J Antimicrob Chemother, 2003, 51, 361-365.

8. $\quad$ Renke H G, Roos P C and Wells S G, N Engl J Med., 1980, 302, 691-692.

9. Linton A L, Clark W F, Driedger A A, Turnbull D I and Lindsay R M, Ann Intern Med., 1980, 93, 735-741.

10. Fontana G, Pitarresi G, Tomarchio V, Carlisi B and San Biagio P L, Biomaterials, 1998, 19, 1009-1017.

11. Schumacher I and Margalit R, J Pharm Sci., 1997, 86, 635-641.

12. Peng L and Nimni M E, J Pharm Pharmacol., 1999, 51, 1135-1141.

13. Martin R A, Anti-infective agents, In: Doerge F, Ed., Wilson and Grisvold's Textbook of Organic Medicinal and Pharmaceutical Chemistry, $8^{\text {th }}$ Ed., Philadelphia, PA: JB Lippincott, 1991, 129-187.

14. Siegel R A, Modeling of drug release from porous polymers, In: Rosoff M, (Ed) Controlled Release of Drugs, Polymers and Aggregate Systems, New York, NY: VcH Publishers, 1989, 46-48.

15. Goncalves T M, Bedor D C, de Abreu L R, de Sousa C E, Rolim C M, Oliveira E J and de Santana D P, Arzneimittel-Forschung, 2008, 58(2), 91-96.

16. Raju Ch B, Sharma H K, Rao G N, Shivakumaran M and Rao Chs, J Pharm Biomed Anal., 2008, 47(1), 218.

17. Lixiao Xu, Huaiyou Wang and Yan Xiao, Spectrochimica Acta Part A: Moleculat and Biomolecular Spectroscopy, 2004, 60(13), 3007-3012.

18. Luo W and Ang C Y W and Thompson H C Jr, J Chromatogr B: Biomed Sci Appl., 1997, 694(2), 401-407.

19. Oscar Alderete, Dinora F. Gonzalez-Esquivel, L. Misael Del Rivero and Nelly Castro Torres. J Chromatogr. B, 2004, 805(2), 353-356.

20. Roncada P, Tomasi L, Stracciari G.L, Ermini L and Strocchia A, J Vet Pharmacol Therapeut., 2000, 23(4), 237-241.

21. Saini G S, Wani T A, Gautam A, Varshney B, Ahmed T, Rajan K. S, Pillai K. K and Paliwal J. K, J Lipid Res., 2006, 47(10), 2340 - 2345.

22. Thorburn Burns D, O'Callaghan M, Franklin Smyth W and Ayling C J, Fresenius' J of Analytical Chemistry, 1991, 340(1), 53-56. 


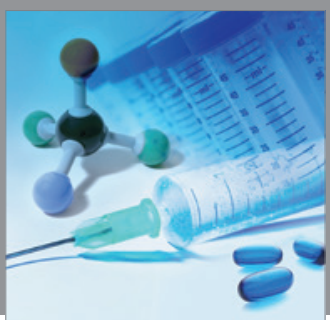

International Journal of

Medicinal Chemistry

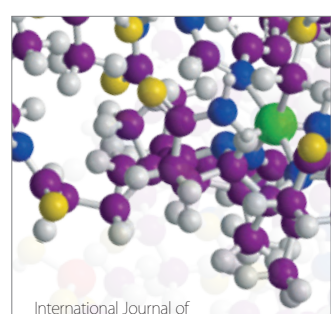

Carbohydrate Chemistry

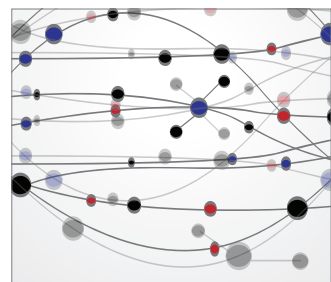

The Scientific World Journal
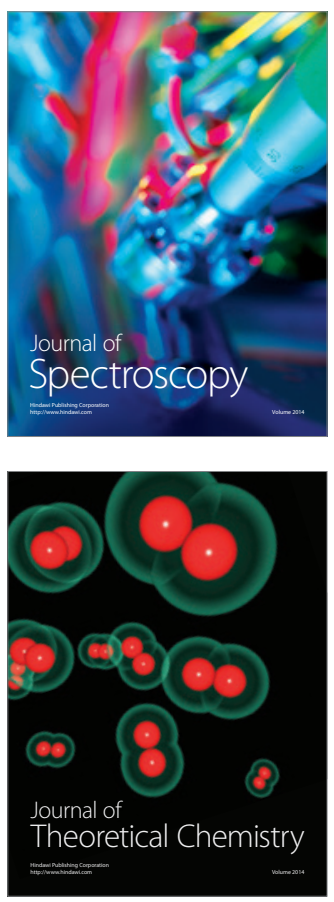
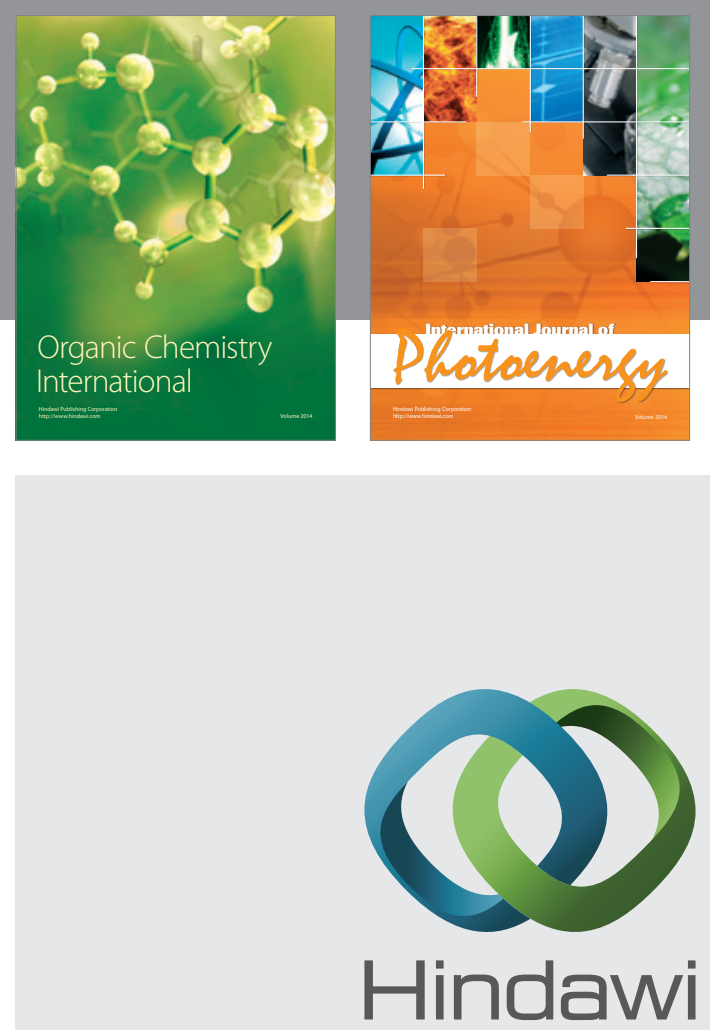

Submit your manuscripts at

http://www.hindawi.com
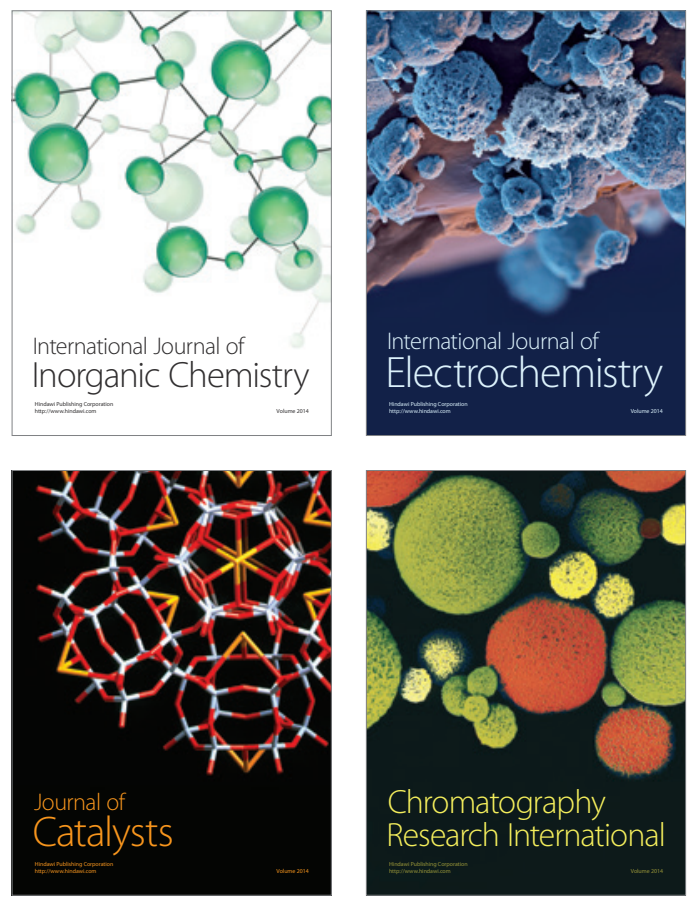
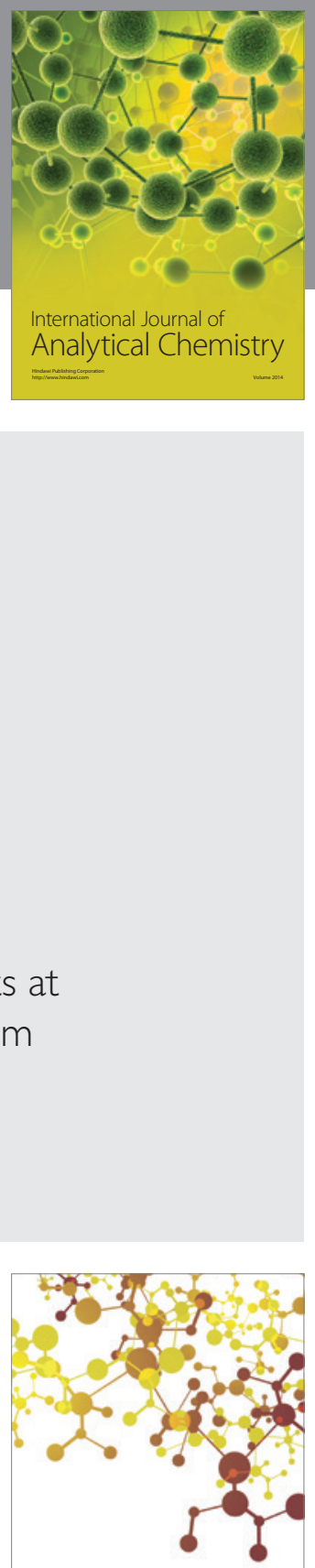

Journal of

Applied Chemistry
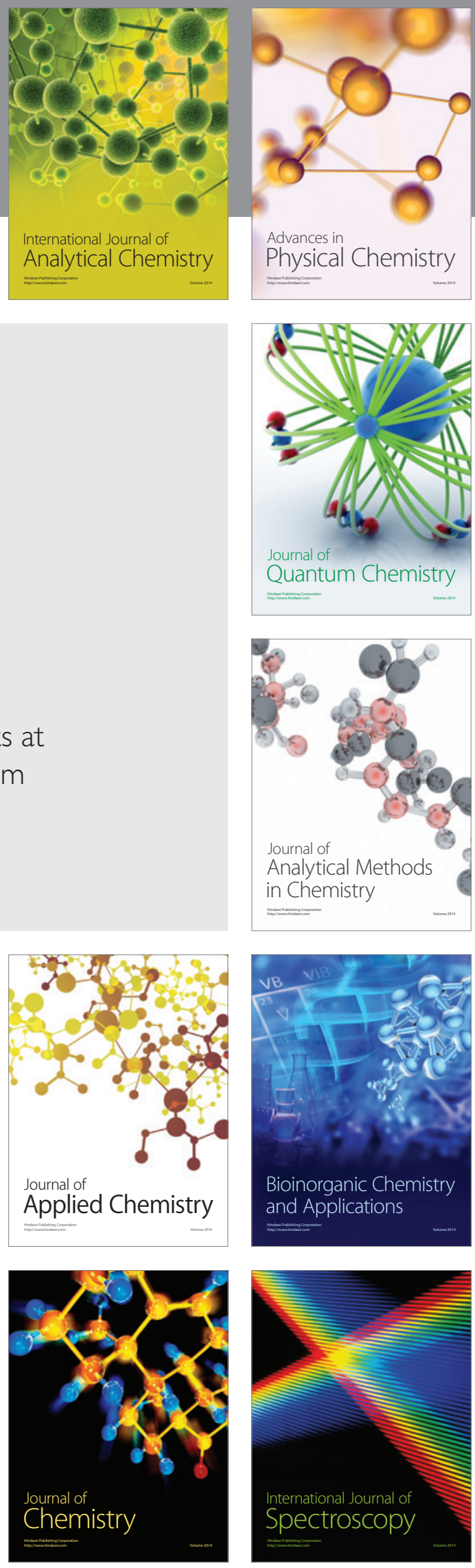